\title{
INFLUÊNCIA DO PODER COERCIVO EM REDES DE EMPRESAS
}

\section{INFLUENCE OF COERCIVE POWER IN CORPORATE NETWORKS}

Recebido em 20.04.2013. Aprovado em 31.10.2013

Avaliado pelo sistema double blind review

DOI: http://dx.doi.org/10.12712/rpca.v7i4.281

\section{Carlos Alberto Chagas Teixeira}

cacteixeira@hotmail.com

Universidade Municipal de São Caetano do Sul - SP - Brasil.

\section{Marcos Antonio Gaspar}

marcos.gaspar@uscs.edu.br

Universidade Municipal de São Caetano do Sul - SP - Brasil.

\section{Milton Carlos Farina}

milton.farina@uscs.edu.br

Universidade Municipal de São Caetano do Sul - SP - Brasil.

\section{Resumo}

O objetivo deste estudo foi identificar e caracterizar a existência do poder coercivo nas relações desenvolvidas por grandes bancos junto às redes de empresas e organizações constituídas em função de estratégias de ações ecoeficientes, voltando-se a análise para as variáveis comprometimento com relacionamento, confiança e cooperação, conforme modelo de Hermans (2003). Conclui-se que há alto nível de poder coercivo exercido pelos bancos analisados junto aos seus parceiros. Porém, tal fenômeno exercido pelos bancos é considerado pelos seus gestores como orientações ou diretrizes estipuladas pelo elo forte da relação, ou seja, o banco. Na visão dos parceiros, este poder é claro e bem recebido, uma vez que não há rejeições das empresas analisadas. Quanto às variáveis de Hermans (2003), na visão dos gestores dos bancos e das empresas, a utilização do poder não diminui o comprometimento e nem a confiança existentes, e também não altera a cooperação entre os envolvidos na rede constituída.

Palavras-chave: Ecoeficiência. Gestão ambiental. Rede de empresas. Estratégia. Bancos.

\section{Abstract}

The aim of this study was to identify and characterize the existence of coercive power in the relations developed by major banks along to networks of companies and organizations formed to develop ecoefficient strategic actions, in order to analyze the variables relationship commitment, trust and cooperation, according to Hermans' model (2003). It was concluded that there is high degree of coercive power exercised by the analyzed banks due to their partners. However, this phenomenon applied by banks is considered by their managers as guidelines set by the strong link of the relationship (bank). From the point of view of the partners, this power is clearly viewed and well received, since there are no rejections from the companies analyzed. About the Hermans model's variables (2003), the banks managers and partner companies managers, the use of power does not diminish the existing commitment and trust, and also does not change the cooperation between those involved in the corporate network.

Keywords: Eco-Efficiency. Environmental management. Corporate network. Strategy. Banks. 


\section{Introdução}

A tendência das empresas em adotar práticas visando a preservação ambiental tem ganhado cada vez mais espaço na atualidade, uma vez que os resultados econômicos vêm demonstrando que não há, necessariamente, conflito entre lucratividade e proteção ao meio ambiente. Assim, constata-se que as discussões sobre os problemas ambientais nas últimas décadas se intensificaram com o aumento da degradação ambiental em todo o planeta. Tal panorama se reflete também nas ações da sociedade em relação às empresas contemporâneas. Também no âmbito acadêmico verifica-se a preocupação em melhor compreender tal fenômeno, uma vez que há um número crescente de pesquisadores voltados ao questionamento dos paradigmas teóricos e conceituais que tratam desta complexa temática.

Há de se enfatizar que dentre as empresas, os bancos são responsáveis por significativos impactos socioambientais, considerando-se o grande número de agências bancárias presentes no país, a elevada quantidade de funcionários envolvidos e os milhões de clientes da indústria bancária como um todo. Assim sendo, alguns insumos e recursos passam a representar um impacto socioambiental significativo, como é o caso, por exemplo, do consumo de papel. A título de exemplo, dados oriundos do Guia de Eco-eficiência para Serviços Bancários (2005) indicam que o consumo médio de papel por funcionário varia de 150 a $300 \mathrm{~kg}$ por ano. No atual panorama, a ausência de qualquer iniciativa para diminuir o consumo deste recurso, representará um impacto crescente na degradação ambiental frente à produção e destinação de papel.

Nos últimos anos, a indústria bancária começou a tratar de forma mais direta o conceito de sustentabilidade, ajustando sua gestão em direção a um caminho responsável, gerando assim ações mais sustentáveis e incorporando conceitos voltados à ecoeficiência junto aos seus parceiros de negócio e à sociedade. A temática ecoeficiência, por sua vez, deixou de ser tratada somente como ferramenta de gestão ambiental, transformando-se em fator capaz de influenciar o comportamento da instituição bancária e de seus funcionários, visando a melhoria de sua imagem e a diminuição de seus custos, viabilizando assim caminhos para alcançar vantagem competitiva duradoura.

Segundo dados de pesquisa realizada pela FEBRABAN - Federação Brasileira de Bancos (2004), os programas e projetos de gerenciamento do impacto ambiental receberam $\mathrm{R} \$ 16,4$ milhões para seu desenvolvimento, por parte de 33,3\% dos bancos abordados. Esses recursos foram aplicados em ações variadas, que vão desde a educação e conscientização sobre o tema ambiental até a adoção de práticas e inovações tecnológicas que permitem redução do consumo de recursos naturais como água e energia. Porém, ações dessa envergadura somente são exequíveis com a participação de diferentes organizações em torno da rede de negócios da instituição bancária.

Assim, outro ponto importante presente nesta pesquisa trata do enfoque de redes de organizações, cuja análise é considerada extremamente relevante para o estágio atual das empresas, levando-se em conta o ambiente integrado e no qual o relacionamento tem sido tratado como ponto fundamental de evolução e crescimento às organizações. Faz-se necessária esta análise sob o ponto de vista das redes uma vez que as empresas atuam como complementadoras umas das outras, em um modelo de cocriação de valor, consolidando os pontos fortes e minimizando os pontos fracos das organizações participantes da rede.

Nesse sentido, este estudo volta seu foco à compreensão do poder coercivo, porventura existente nos relacionamentos entre o banco e sua rede de negócios estabelecida, quando do 


\section{INFLUÊNCIA DO PODER COERCIVO EM REDES DE EMPRESAS}

desenvolvimento de ações voltadas à sustentabilidade. Assim, optou-se pelo modelo de Hermans (2003), por ser o mais aderente ao enfoque do presente estudo ao abordar o poder coercivo nesse tipo de aglomeração de organizações em relação às variáveis comprometimento com o relacionamento, confiança e, por fim, cooperação.

\section{Estratégia no contexto da indústria bancária}

Não se pode falar em estratégia sem fazer menção à competição inerente ao contexto no qual as empresas contemporâneas estão inseridas. Não obstante, outro aspecto a ser considerado no pensamento estratégico atual refere-se à limitação dos recursos naturais disponíveis no planeta. A partir desses fatores restritivos, novas formas de negócio que abram espaço de mercado para a criação de novas demandas e melhorias para a sociedade têm sido reconhecidas. Assim, a exploração de novos espaços de mercado gera um ganho para as empresas, para a sociedade, para os trabalhadores e, inclusive, para a competição em si. 0 pensamento estratégico direcionado por esta visão de mercado pode proporcionar um desempenho melhor a todos os envolvidos (KIM ; MAUBORGNE, 2007).

0 fator estratégico busca uma vantagem competitiva baseada na redução de custos da matéria prima e do produto final, o que faz com que fusões ou aquisições sejam parte da estratégia competitiva de uma indústria. Tal expediente tem ocorrido com bastante frequência na indústria bancária brasileira (JARILLO, 1998).

Em indústrias como a bancária, na qual os produtos são os serviços oferecidos, observa-se que na década de 1970 no Brasil havia uma definição limitada e estável de produtos (pagamentos, empréstimos e investimentos) e os bancos atendiam mercados segmentados, atuando de forma complementar entre si. Tais características sofreram alterações significativas ao longo das últimas décadas e os bancos passaram a operar como bancos múltiplos por meio de redes de agências em contínua expansão. Desta forma, na realidade atual os produtos oferecidos estão muito mais diversificados, porém os principais bancos múltiplos oferecem produtos muito similares e, com isto, a estratégia em termos de custos passa a ser vital, principalmente depois da segunda metade da década de 1990, momento a partir do qual a economia passou a ficar cada vez mais estabilizada (LARANGEIRA, 2001).

Assim sendo, os estudos referentes à estratégia ou à administração estratégica revestem-se em um fenômeno de formação relativamente mais recente, especialmente em se tratando de sua prática especificamente em bancos. No entanto, é um campo de estudo extremamente dinâmico em sua capacidade de criar abordagens teóricas diferenciadas, desde seu surgimento a partir da segunda metade do século XX (VASCONCELOS, 2001).

A estratégia guarda íntima relação com o potencial de competitividade que a empresa apresenta no mercado em que atua, até porque a competitividade é condição natural na qual as empresas devem se encaixar, caso almejem seu crescimento ou até mesmo sua própria sobrevivência. Machado e Fonseca (2010, p. 34) ressaltam a "importância da competitividade até mesmo a partir dos padrões de comportamentos impostos pela globalização, assumindo a responsabilidade da competência e a busca pelos indicadores de desenvolvimento e questões técnicas". Neste contexto, é esperado que as organizações busquem técnicas, bem como invistam em estudos para assumirem uma competitividade estratégica, fazendo com que os clientes na hora da escolha de produtos e serviços optem pela empresa.

Estudiosos do tema têm se inclinado a estudar as estratégias competitivas em diferentes 
setores, utilizando-se de argumentos e ações de acordo com cada setor. De fato, deve-se observar que os estudos passam a ter como foco o consumidor final, sempre pensando em estratégias que levem à confiança, fidelidade, lealdade e satisfação do cliente. É neste mesmo momento histórico (década de 1970) que os estudos começaram a voltar-se ao tema do meio ambiente como foco de medidas estratégicas. Galdino et al. (2004) voltaram seus estudos para a estratégia ambiental, fazendo uma revisão teórica de custos na indústria do petróleo. No estudo, os autores demonstram que no novo quadro socioeconômico, as empresas devem repensar suas estratégias competitivas considerando o meio ambiente.

Estudos como o de Luz et al. (2006) voltam seu foco à mensuração do desempenho ambiental como critério de apoio à tomada de decisões na empresa, fator esse que consagra a consciência ambiental como ferramenta para a tomada de decisões estratégicas competitivas. Tal ênfase dá-se de forma mais evidente em função do incentivo dos certificados ambientais que passaram a existir após a década de 1980, sendo um dos mais recentes e respeitados, o Sistema de Gestão Ambiental (SGA), certificado conforme a norma ISO 14001:2004.

Neste contexto, cabe esclarecer o porquê do interesse dos estudos voltados ao meio ambiente, e como estas pesquisas tornaram-se fonte de estratégia competitiva e até mesmo responsáveis pela tomada de decisão na empresa. Assim, como se demonstrará a seguir, a Responsabilidade Social começa a ser alvo de estudos devido à sua dimensão estratégica às empresas contemporâneas. Segundo Demajorovic (2003), há um claro aumento na conscientização empresarial em torno das questões ambientais, principalmente quando as organizações passam a admitir que tal postura possa servir como ferramenta de contribuição para uma maior competitividade.

Isto se deve, segundo Coutinho et al. (2002), ao fato de que a responsabilidade social em sua faceta voltada à ecoeficiência reveste-se de importantes fatores a serem considerados no desenvolvimento do pensamento estratégico. 0 autor sustenta que a ecoeficiência se faz importante às empresas contemporâneas "por implicar num ambiente de trabalho mais motivador e eficiente, por contribuir para uma imagem institucional positiva e por favorecer o estabelecimento de relacionamentos calcados em maior comprometimento com seus parceiros de negócio (COUTINHO et al., 2002, p. 76).

Como pôde ser evidenciado até aqui, a estratégia surge então como item premente no atual contexto de acirrada competitividade da indústria bancária. E, em seu bojo, também se faz mandatória a observância pelos bancos de questões relacionadas à gestão ambiental e ações voltadas à ecoeficiência.

\section{Ecoeficiência}

A estratégia fundamentada na ecoeficiência tem origem na década de 1980, baseada na ideia geral de que a sociedade pode ser transformada a fim de resolver os problemas ambientais que começavam a se agravar à época. Um pressuposto básico ao desenvolvimento deste tema repousa na discussão sobre a adaptação das atividades empresariais ao crescimento econômico e ao desenvolvimento industrial, ou seja, a produzir mais com menos (AALL; HUSABO, 2010).

Dahlsrud (2009) define ecoeficiência como a redução da intensidade com que as matériasprimas, materiais e consumo de energia por unidade de produto são utilizadas, buscando-se assim melhorar as possibilidades de reciclagem e reutilização, ampliando-se a regeneração de 


\section{INFLUÊNCIA DO PODER COERCIVO EM REDES DE EMPRESAS}

recursos, aumentando a durabilidade dos produtos e as chances de reciclagem dos componentes, reduzindo assim a dispersão de substâncias tóxicas no ambiente.

Para Co; Booth; Louis (2006), o termo ecoeficiência foi proposto em 1990 por dois pesquisadores suíços: Schaltegger e Sturm. A nomenclatura ecoeficiência foi formalmente definida e aprovada pelo Conselho Empresarial Mundial para o Desenvolvimento Sustentável (WBCSD) em 1991, como sendo a entrega de mercadorias e serviços a preços competitivos e que satisfaçam as necessidades humanas, trazendo qualidade de vida, enquanto progressivamente reduzem os impactos ecológicos e a intensidade de recursos durante todo o ciclo de vida do produto, a um nível pelo menos em linha com a capacidade de carga da Terra.

Já na visão de Desimone e Popoff (2000), a ecoeficiência surgiu em razão da necessidade das organizações diminuírem a emissão de gás carbônico e demais gases geradores do efeito estufa. Kolarz e Korol (2010) argumentam que ecoeficiência seja um novo conceito de gestão ambiental que integra as considerações ambientais com análise econômica para melhorar produtos e tecnologias. Ou seja, ecoeficiência é uma ferramenta estratégica da empresa, configurando-se num fator-chave para seu desenvolvimento sustentável. A correta análise e emprego da ecoeficiência pela empresa permite encontrar a solução mais eficaz, levando-se em conta aspectos econômicos e de compatibilidade ambiental de produtos e tecnologias.

Quanto ao objetivo da ecoeficiência, Thant e Charmondusit (2010) afirmam que a ecoeficiência busca maximizar a criação de valor, apesar da minimização do uso de recursos e emissões de poluentes. Dessa forma, a mensuração dos resultados de uma estratégia ecoeficiente é importante para medir a dissociação entre o crescimento econômico e a pressão ambiental. Assim, conforme expõem Michelsen e Dahlsrud (2009), os principais objetivos da análise de ecoeficiência são: redução do consumo de recursos, redução do impacto ambiental, aumento do valor do produto agregado, aumento da eficiência econômica da produção e, por fim, redução do impacto ambiental.

Sob o ponto de vista de Barbieri (2007), a ecoeficiência baseia-se na ideia de que a redução de materiais e energia por unidade de produto ou serviço aumente a competitividade da empresa e, ao mesmo tempo, reduza as pressões sobre o meio ambiente, seja como fonte de recurso, seja como depósito de resíduos. Ou seja, a ecoeficiência pode ser vista como uma ferramenta de gestão que representa uma forma para solucionar problemas cada vez mais latentes no cotidiano corporativo, como é o caso de problemas que afetem o meio ambiente.

Assim, a ecoeficiência tem assumido um papel cada vez maior nas estratégias de gestão ambiental das empresas, constituindo-se numa ferramenta essencial para conciliar crescimento econômico e melhoria do desempenho ambiental. Nessa seara, a ecoeficiência passa a ser entendida como um determinado nível de eficiência organizacional alcançado pela empresa. Nível esse caracterizado pela entrega de bens e serviços a preços competitivos, que satisfazem as necessidades humanas e melhoram a qualidade de vida, ao mesmo tempo que minimizam os impactos ambientais e a intensidade do uso de recursos naturais a um ponto ao qual o meio ambiente suporta em um equilíbrio dinâmico, conforme exposto pelo World Business Council for Sustainable Development - Eco Efficiency (2002).

Na visão de Virjan (2011), a ecoeficiência é motivada não apenas por questões relacionadas à proteção ao meio ambiente, mas também pela perspectiva de economia financeira importante sob a forma de custos mais baixos de energia e água, além de menos despesas com matériasprimas, materiais e combustíveis, dentre outros. A nova economia deve ser a economia do mundo moderno e das necessidades humanas, de modo a criar um consenso entre as necessidades humanas e as necessidades do meio ambiente. Nesse contexto, as empresas 
podem assumir papel significativo na criação desse consenso.

Hertwich (2009) argumenta de forma crítica a respeito do debate sobre a ecoeficiência e modernização ecológica, discorrendo que este tem se concentrado na eficiência da produção industrial, em consenso com o meio ambiente; isto é, o uso de recursos ou emissões e resíduos por unidade de produção ou por unidade de preço. Porém, o resultado final tem sido objeto de pouca atenção, ou seja, se a aplicação de uma estratégia de ecoeficiência tem realmente reduzido a pressão ambiental na sociedade como um todo ou apenas mudou literalmente a pressão para outras ações relacionadas às atividades econômicas.

Vale ainda verificar a visão proporcionada pela Organização para a Cooperação e o Desenvolvimento Econômico (OCDE), pela qual a ecoeficiência pode ser compreendida como a eficiência com que os recursos ecológicos são utilizados para atender as necessidades humanas. Nesse contexto, deve-se considerar o resultado obtido a partir do valor dos produtos e serviços gerados por uma empresa, um setor econômico ou ainda, um país; dividido pela soma das pressões ambientais geradas pelas empresas e setores (LEHNI, 2000). Os conceitos de ecoeficiência expostos até aqui indicam a existência de uma importante ligação entre eficiência dos recursos e produtividade, lucratividade e responsabilidade ambiental da empresa. Ou seja, a ecoeficiência assume um sentido de melhoria econômica das empresas, pois busca eliminar resíduos e utilizar recursos de forma mais coerente. Assim, empresas ecoeficientes podem obter redução dos custos e se tornarem mais competitivas, alcançando vantagens em novos mercados, principalmente em mercados nos quais as exigências para produtos sustentáveis são rigorosas (DIAZ e PIRES, 2005).

A ecoeficiência gera melhoria econômica nas empresas, minimizando os resíduos e utilizando os recursos de forma mais adequada. Empresas ecoeficientes podem reduzir custos e serem mais competitivas, aplicando procedimentos ambientalmente corretos, sem comprometerem a qualidade dos produtos. Estes procedimentos se baseiam em conceitos tais como: prevenção da poluição, redução do consumo de matéria-prima, redução e minimização do desperdício e produção limpa (WBCSD, 1996).

Conforme resumido na concepção de Mirata e Emtairah (2005), a ecoeficiência conceitualmente trata especificamente de uma nova maneira de a sociedade se relacionar com seu ambiente, de forma a garantir a sua própria continuidade e a de seu meio externo, sendo que as empresas assumem importante papel nesse novo modelo. Em outras palavras, a ecoeficiência pode ser vista como o uso eficiente dos recursos naturais, sem deixar de gerar maior produtividade e lucratividade, associado (ou tendo como consequência) à maior responsabilidade ambiental da empresa/indústria, principalmente quando aplicada em redes organizacionais. Ou seja, o uso mais eficiente de matérias-primas e de energia é capaz de reduzir custos econômicos e os impactos ambientais da produção para todos os envolvidos na cadeia de negócios da rede de empresas estabelecida, não dependendo exclusivamente de uma única empresa.

\section{Redes de Empresas}

O conceito de rede é definido por Grandori e Soda (1995) como um conjunto de nós conectados por relações. 0 seu uso pela teoria organizacional e administrativa é uma figura de linguagem comparativa, uma metáfora que se torna instrumento para criar e compreender as organizações e seus relacionamentos. Rachid (2000), por sua vez, afirma que alguns autores utilizam o termo rede para se referirem a uma forma particular de organização, buscando 


\section{INFLUÊNCIA DO PODER COERCIVO EM REDES DE EMPRESAS}

assim prescrever como uma organização deve ser para se tornar competitiva. A autora complementa que o termo 'organização em rede' está associado a uma lógica de ação coletiva que permite a cooperação a longo prazo entre as diferentes organizações envolvidas.

Cândido e Abreu (2004) argumentam que as redes consistem num conjunto de informações interligadas por meio de relações específicas, estruturadas a partir da definição dos papéis, atribuições e relações entre os elementos participantes. Isto envolve aspectos relacionados à estrutura, heterogeneidade e hierarquia, os quais precisam ser devidamente definidos e explicitados (CÂNDIDO e ABREU, 2004). Amato Neto (2000) indica que a formação de redes de empresas pode surgir de uma necessidade empresarial (não planejada) ou de uma necessidade estratégica (planejada).

Neste aspecto, considera-se que são muitas as formas para classificar e diferenciar os tipos de redes: dependência estratégica das partes; formação relacional; flexibilidade da produção; integração da produção; grau de compartilhamento das funções; objetivos e amplitude destes; tempo de duração; setores industriais envolvidos; grau e tipo de ligação e vínculos entre as partes e ainda a liderança de organizações centrais, dentre outras possibilidades (FARIAS FILHO; CASTANHA; PORTO, 2009). Conforme argumentam Venturini et al. (2009), as empresas que integram uma rede conseguem reduzir custos, dividir riscos, conquistar novos mercados, qualificar produtos e serviços e ter acesso às novas tecnologias.

A caracterização de redes de empresas visa diretamente a busca de um retorno que muitas vezes pode transformar-se em vantagem competitiva no mercado em que atuam as empresas participantes da rede. A partir dessa possibilidade, diversos autores vêm desenvolvendo construtos que buscam demonstrar diferentes vertentes que balizam o funcionamento das empresas em uma rede de organizações. Dentre essas vertentes, o comprometimento, a confiança e a cooperação são aspectos fundamentais para a realização do objetivo final das empresas atuantes na rede de organizações.

Ferreira (1999, p. 516) define comprometimento como o "ato ou fato de comprometer-se. Comprometer, do latim compromittere, apresenta as seguintes definições: a) fazer assumir compromisso; obrigar por compromisso, b) implicar; envolver, c) dar, como garantia; empenhar, d) expor a perigo; arriscar, aventurar, e) pôr (alguém) em má situação ou em situação suspeita, f) assumir compromisso".

Delfim Neto (2009, p. 47) sintetiza bem a importância da confiança ao refletir: "[...] qual é a origem da sociedade?... Então, a confiança precede a sociedade. Ela é o cimento, o fator catalítico que faz funcionar a sociedade". Na visão de Lundin (2007), a confiança tem sido considerada um pré-requisito da cooperação interorganizacional. Em outros termos, a confiança configura-se como um antecedente relevante à cooperação. Para este autor, a cooperação depende da existência da confiança mútua e da congruência entre os objetivos dos envolvidos, sendo que a ausência de simultaneidade entre estes dois últimos construtos poderá dificultar a cooperação entre as organizações.

Hanna e Walsh (2008) argumentam que a cooperação permite o estabelecimento de conexões entre os agentes ou a constituição de relações estruturadas (socialmente e economicamente) em rede, no sentido de atender aos objetivos individuais e coletivos dos seus participantes. Em outros termos, a construção de relacionamentos de interesses econômico-sociais entre as organizações poderá produzir benefícios recíprocos e inclusivos econômica e socialmente. Os autores destacam que a obtenção e manutenção destes benefícios derivados da cooperação, depende de diversos fatores, a exemplo, da cultura local e da existência de parceiros de negócios comprometidos e com objetivos semelhantes. 
Assim sendo, confiança, comprometimento e cooperação são requesitos fundamentais ao funcionamento de uma rede de organizações. A partir desta premissa, pesquisadores buscam melhor compreender o fenômeno das redes de organizações a partir da elaboração de constructos que expressem as principais características desses relacionamentos interorganizacionais.

\section{Constructos de Redes de Empresas}

A definição de um constructo implica a análise de modelos teóricos capazes de elucidar um determinado fenômeno, de modo que a elaboração dos itens não seja meramente intuitiva. Sobre a definição operacional, por sua vez, o construto se fundamenta pela possibilidade de validação das relações expostas por meio da mensuração destas (PASQUALI, 1999).

Existem diferentes modelos de constructos relativos às variáveis de relacionamento entre as empresas participantes de uma rede, a partir da visão de diferentes autores: a) Modelo KVM de Morgan e Hunt (1994) - no qual o comprometimento e a confiança desempenham papel central para o sucesso do relacionamento entre clientes e fornecedores; b) Modelo de Morgan e Hunt com a variável poder (1994) - é uma variação do modelo anterior, que contempla a variável poder na forma coerciva. Considerando-se um relacionamento de longo prazo, há uma menor incidência do uso do poder e, por fim, c) Modelo de Soetomo (2001) diferentemente de Morgan e Hunt (1994), o autor sugere que a variável poder possa influenciar de diferentes maneiras as demais variáveis do construto, não necessariamente de forma negativa.

A demonstração dos constructos anteriormente expostos servirá como alicerce para o delineamento da presente pesquisa, na qual algumas variáveis precisam ser melhor compreendidas, principalmente quando utilizadas nas ações de ecoeficiência desenvolvidas pelos participantes das redes de empresas e organizações constituídas junto aos principais bancos privados atuantes na indústria bancária brasileira. Em razão disto, optou-se pelo modelo de Hermans (2003), por ser o mais aderente ao tema de pesquisa.

Hermans (2003) utilizou como parâmetro o modelo de Morgan e Hunt (1994), porém somente com o emprego das variáveis comprometimento, confiança, poder coercivo e cooperação, conforme exibe a Figura 1. A pesquisa foi efetuada junto a gerentes de canais de marketing associados ao Warehousing Education Research Council. Os pesquisados trabalhavam em empresas que eram clientes de fornecedores no canal de distribuição. Hermans (2003) utilizou uma subamostra, na qual os fornecedores tinham maior habilidade de forçar as empresas a aceitarem suas exigências, isto é, alto poder coercivo exercido. Com isto, o autor concluiu que a utilização de alto nível de poder coercivo diminui a confiança e o comprometimento, porém não diminui a cooperação entre os integrantes da rede. 


\section{INFLUÊNCIA Do PODER COERCIVO EM REDES DE EMPRESAS}

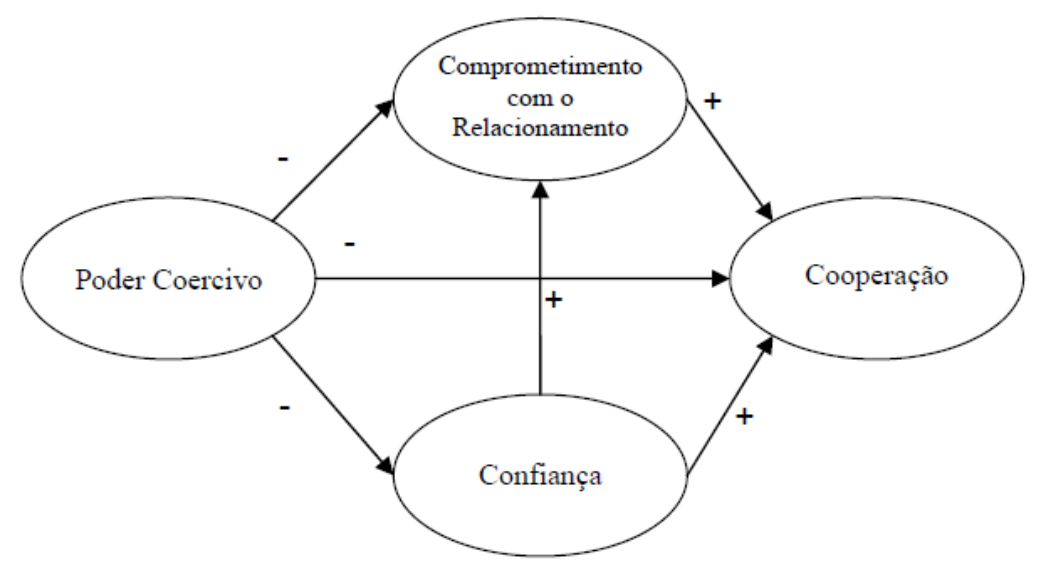

Figura 1 - Modelo de Hermans

Fonte: Hermans (2003, p. 47)

Anvari e Amin (2010) corroboraram os achados de Hermans (2003). Os autores realizaram uma pesquisa com 504 empresas de tapetes na Índia, com o objetivo de estabelecer a relação entre comprometimento, envolvimento, satisfação, qualidade do serviço e conhecimento organizacional, com a propensão de deixar os relacionamentos interorganizacionais. 0 fator de maior importância na propensão de deixar o relacionamento foi a qualidade do serviço, enquanto que o efeito mediador do comprometimento foi pequeno.

\section{Metodologia da pesquisa}

Para alcançar os objetivos do presente estudo, foi realizada uma pesquisa exploratória de caráter qualitativo em duas etapas, a saber: a primeira empregou uma pesquisa bibliográfica que buscou conhecimentos nas fontes bibliográficas, compreendendo artigos científicos, publicações periódicas, sites, balanços financeiros e informações disponíveis sobre os principais bancos privados atuantes no Brasil. Esta primeira etapa teve como objetivo conhecer e caracterizar as estratégias e ações voltadas à ecoeficiência adotadas pelos bancos privados analisados junto às respectivas redes de empresas e organizações.

A segunda etapa da pesquisa envolveu entrevistas com roteiro semi-estruturado aplicadas aos executivos e gestores de áreas administrativas ligadas à sustentabilidade nos bancos pesquisados, bem como com aos gestores de empresas e organizações constituintes de cada rede analisada. Especificamente em relação às organizações envolvidas na rede de empresas dos respectivos bancos, buscou-se entrevistar os representantes com poder de decisão em organizações tais como fornecedores, instituições de ensino e ONGs.

0 universo contemplado nesta pesquisa refere-se aos 126 bancos oficialmente atuantes no país, de acordo com dados da FEBRABAN (2011). Dentre esse universo, optou-se por prospectar como amostra os três maiores bancos múltiplos privados atuantes no Brasil: Itaú, Bradesco e Santander. 0 critério de seleção da amostra deveu-se à representatividade desses bancos no contexto nacional, uma vez que, juntos tais bancos detêm $55 \%$ dos ativos, $56 \%$ dos lucros, 65\% dos funcionários e 62\% das agências (FEBRABAN, 2011).

Assim, foram entrevistados dois gestores de cada banco (doravante denominados bancos A, B 
e C) e os representantes das organizações parceiras inseridas na rede de empresas analisada, conforme caracterizações a seguir descritas:

A) Gestores dos bancos analisados:

- GBA 1 (Gestor 1 do Banco A) - Cargo: supervisor de sustentabilidade sênior, tempo no Cargo: 1 ano e 10 Meses, tempo de atuação na indústria bancária: 4 anos, tempo de atuação no nanco: 4 anos, tempo de atuação em questões voltadas à sustentabilidade e ecoeficiência: 2 anos;

- GBA 2 (Gestor 2 do Banco A) - Cargo: analista de sustentabilidade pleno, tempo no cargo: 4 meses, tempo de atuação na indústria bancária: 5 anos, tempo de atuação no banco: 5 anos, tempo de atuação em questões voltadas à sustentabilidade e ecoeficiência: 2 anos;

- GBB 1 (Gestor 1 do Banco B) - cargo: sub-gerente executivo de responsabilidade socioambiental, tempo no cargo: 3 anos, tempo de atuação na indústria bancária: 22 anos, tempo de atuação no banco: 14 anos, tempo de atuação em questões voltadas à sustentabilidade e ecoeficiência: 5 anos;

- GBB 2 (Gestor 2 do Banco B) - cargo: gerente executivo de responsabilidade socioambiental, tempo no cargo: 7 anos, tempo de atuação na indústria bancária: 18 anos, tempo de atuação no banco: 15 anos, tempo de atuação em questões voltadas à sustentabilidade e ecoeficiência: 10 anos;

- GBC 1 (Gestor 1 do Banco C) - cargo: gerente de projetos de Sustentabilidade, tempo de cargo: 1 ano e 2 meses, tempo de atuação na indústria bancária: 16 anos, tempo de atuação no banco: 16 anos, tempo de atuação em questões voltadas à sustentabilidade e ecoeficiência: 9 anos;

- GBC 2 (Gestor 2 do Banco C) - cargo: analista de desenvolvimento sustentável sênior, tempo de cargo: 4 anos e meio, tempo de atuação na indústria bancária: 7 anos, tempo de atuação no banco: 7 anos, tempo de atuação em questões voltadas à sustentabilidade e ecoeficiência: 12 anos.

B) Gestores de organizações e empresas da rede formada a partir dos bancos analisados:

- PBA 1 (Parceiro 1 do Banco A - Fornecedor) - cargo: sócio - gerente de qualidade e sustentabilidade, tempo de cargo: 4 anos, tempo de atuação na empresa: 7 anos e meio, tempo de atuação em questões voltadas à sustentabilidade e ecoeficiência: 4 anos;

- PBA 2 (Parceiro 2 do Banco A - Organização não governamental - ONG) - cargo: diretora de comunicação, tempo de cargo: 15 anos, tempo de atuação na empresa: 15 anos, tempo de atuação em questões voltadas à sustentabilidade e ecoeficiência: 15 anos;

- PBB 1 (Parceiro 1 do Banco B - Fornecedor) - cargo: gerente de qualidade e sustentabilidade, tempo de cargo: 4 anos, tempo de atuação na empresa: 7 anos e meio, tempo de atuação em questões voltadas à sustentabilidade e ecoeficiência: 4 anos;

- PBB 2 (Parceiro 2 do Banco B - Fornecedor) - cargo: proprietário, tempo de cargo: 8 anos, tempo de atuação na empresa: 8 anos, tempo de atuação em questões voltadas à sustentabilidade e ecoeficiência: 3 anos e meio

- PBC 1 (Parceiro 1 do Banco C - Fornecedor) - cargo: gerente de qualidade e sustentabilidade, tempo de cargo: 4 anos, tempo de atuação na empresa: 7 anos e meio, tempo de atuação em questões voltadas à sustentabilidade e ecoeficiência: 4 anos;

- PBC 2 (Parceiro 2 do Banco C - Organização não governamental - ONG) - cargo: presidente, 


\section{INFLUÊNCIA DO PODER COERCIVO EM REDES DE EMPRESAS}

tempo de cargo: 3 anos, tempo de atuação na empresa: 3 anos, tempo de atuação em questões voltadas à sustentabilidade e ecoeficiência: 12 anos.

\section{Apresentação e análise dos resultados}

\section{Breve caracterização dos maiores bancos privados atuantes no país}

A seguir é apresentada uma breve caracterização dos bancos privados analisados na pesquisa de campo efetuada.

ITAÚ S/A

O Banco Itaú foi fundado 1943 na cidade de São Paulo (SP). É um banco com forte presença no varejo, marcada por uma ampla rede de atendimento. 0 banco possuía 2.931 agências, 783 PABs (posto de atendimento bancário) e 22.023 caixas eletrônicos. A fusão em 2008 com Unibanco elevou estes números para 3.766 agências, 5.082 PABs e mais de 30.000 caixas eletrônicos. 0 banco também está presente com subsidiárias na Argentina, Chile, Paraguai, Uruguai, Bahamas, Ilhas Cayman, Nova York, Portugal, Inglaterra, Espanha, Alemanha, França, China e Japão.

\section{BRADESCO S/A}

O Banco Bradesco foi fundado em 1943 no município de Marília (SP) e atualmente estende-se por todo o país, tendo sua rede de atendimento composta por 4.444 agências, 1.368 PABs, 1.608 PAAs (posto de atendimento avançado), 17.922 pontos de atendimento próprios e 35.007 pontos de atendimento em terceiros (sendo 12.323 pontos da rede Banco 24 horas). Presente em todos os municípios brasileiros. 0 banco também atua em outros países, como Argentina, Japão, Inglaterra, Luxemburgo e Estados Unidos, por meio de agências e subsidiárias.

\section{SANTANDER BRASIL S/A}

O Banco Santander foi fundado em 1857, tendo origem espanhola. É uma grande instituição financeira mundial, com presença em mais de 22 países, entre eles Reino Unido, Suíça, Rússia, Hungria, República Tcheca e Marrocos. Já no Brasil sua atuação deu-se a partir de 1982 e, com a aquisição do Banco Real em 2009, o Santander passou a ocupar a terceira posição no ranking nacional de bancos privados com 2.463 agências, 4.445 PABs e mais de 18.500 caixas eletrônicos.

Principais ações sustentáveis desenvolvidas pelos maiores bancos privados atuantes no país

O Quadro 1 apresenta as principais ações sustentáveis promovidas pelos três maiores bancos privados atuantes no Brasil. 
Quadro 1

\section{Principais ações sustentáveis realizadas pelas redes de empresas formadas a partir dos maiores}

\begin{tabular}{|c|c|}
\hline Bancos & Principais ações sustentáveis \\
\hline Itaú & $\begin{array}{l}\text { - PIC Natureza lançado com o apoio da WWF-Brasil } \\
\text { - Fundação Itaú Social } \\
\text { - Prêmio Itaú UNICEF } \\
\text { - TI Verde } \\
\text { - Ecomudança } \\
\text { - Educação Financeira } \\
\text { - Redução de } 17 \% \text { nos consumos de água e papéis } \\
\text { - Programa de coleta seletiva de plásticos e alumínios } \\
\text { - Uso louças e metais projetados para reduzir o consumo de água } \\
\text { - Programa de coleta seletiva de plásticos e alumínios } \\
\text { - Cartuchos usados em impressoras e copiadoras são doados a entidades carentes } \\
\text { - Ações como venda de aparas de papel }\end{array}$ \\
\hline Bradesco & $\begin{array}{l}\text { - Fundação Bradesco com } 180.000 \text { alunos atendidos } \\
\text { - Fundação SOS Mata Atlântica } \\
\text { - Primeira instituição brasileira a compensar a sua emissão de CO2 } \\
\text { - Certificação ISO } 14001 \\
\text { - Programa Gestão da Ecoeficiência } \\
\text { - Reciclagem, inovações tecnológicas e economia no uso de recursos e materiais. } \\
\text { - Comitê Executivo de Eficiência } \\
\text { - Treinamentos: ética, finanças sustentáveis e língua brasileira de sinais (Libras) } \\
\text { - Comunicação interna = mensagens eletrônicas, do informativo Sempre em Dia via } \\
\text { Intranet, da revista interna Interação, de cartilhas temáticas e de programas da } \\
\text { TV Bradesco, levando em conta sugestões dos funcionários }\end{array}$ \\
\hline Santander & $\begin{array}{l}\text { - Projeto Escola Brasil } \\
\text { - Projeto Universidades } \\
\text { - Projeto Cultura Ecoeficiente } \\
\text { - Patrocínio para recuperação do Rio Pinheiros } \\
\text { - Universidade Solidária } \\
\text { - Três pilares: reduzir, reutilizar e reciclar } \\
\text { - Distribuição de canecas que substituem os copos plásticos descartáveis } \\
\text { - Sistema de coleta seletiva nos prédios administrativos } \\
\text { - O Banco doa 100\% dos resíduos recicláveis às instituições beneficentes } \\
\text { - Sobras orgânicas, oriundas de seu refeitório, são entregues a uma empresa } \\
\text { privada que descarrega o material em um aterro sanitário no bairro do Jaguaré } \\
\text { (São Paulo), que posteriormente o transforma em adubo orgânico } \\
\text { - Os prédios administrativos e 98\% das agências têm coleta seletiva } \\
\text { - Lâmpadas, pilhas, baterias e cartuchos de impressoras passaram a ter destinação } \\
\text { devidamente adequada. } \\
\text { - O uso do papel certificado, de baixo impacto ambiental é incentivado } \\
\text { - Monitoramento das emissões de gases de efeito estufa e um plano de redução/ } \\
\text { compensação dessas emissões }\end{array}$ \\
\hline
\end{tabular}

Fonte: elaborado pelos autores a partir dos balanços sociais dos bancos Itaú (2011), Bradesco (2011) e Santander (2012).

\section{Análise dos parâmetros do Modelo de Hermans (2003)}

Neste tópico são expostos os resultados auferidos na pesquisa de campo a respeito dos parâmetros presentes no Modelo de Hermans (2003). 


\section{INFLUÊNCIA DO PODER COERCIVO EM REDES DE EMPRESAS}

\section{$\underline{\text { Poder Coercivo }}$}

Na variável Poder Coercivo, Hermans (2003) utilizou uma subamostra, na qual os fornecedores tinham maior habilidade de forçar as empresas a aceitarem suas exigências, isto é, alto poder coercivo, que na sua visão diminuía a confiança e o comprometimento, porém, não diminuía a cooperação entre os integrantes da rede de empresas. Já para bancos pesquisados e seus parceiros na rede de organizações e empresas constituída, a visão é um pouco diferente.

Para os parceiros da rede de negócios dos Bancos A, B e C, o poder coercivo é bem claro, uma vez que os bancos forçam as empresas e organizações a aceitarem o seu método de trabalho. Porém, para os gestores dos bancos analisados, há um claro poder, mas não considerado coercivo, conforme evidenciado nas falas dos gestores dos bancos: "Eu enxergo o banco como um líder nas ações, traçando objetivos e monitorando para que tudo fique da melhor forma, que os resultados sejam os melhores para todo mundo" (GBA 1) e ainda "Acho a palavra 'poder' muito forte. Acho que há uma liderança e objetivos a serem desenvolvidos, onde temos interesses mútuos. Tanto da minha parte, quando da parte das outras pessoas envolvidas nas ações" (GBA 2).

Já para os parceiros atuantes nas redes de empresas e organizações constituídas para ações ecoeficientes, há sim um poder coercivo que é aceito e considerado muito claro e natural, conforme relatam a seguir os gestores das organizações parceiras entrevistadas: "Sempre há, não tem como se relacionar com empresas grandes como o banco e eles não imporem suas vontades e suas exigências. Neste tipo de parceria, isto é muito normal" (PBA 1) e também "Há com certeza, precisamos estar sempre atento às exigências que o banco faz, isto já faz parte do nosso trabalho" (PBC 1).

\section{Poder Coercivo x Comprometimento com o Relacionamento}

Durante as entrevistas realizadas com os gestores dos bancos, ficou claro que o uso do poder coercivo não interfere nas outras variáveis, tais como o comprometimento com o relacionamento nos bancos nas redes de empresas e organizações pesquisadas. Conforme relatos, quando os sujeitos foram questionados se o uso do poder aumenta o comprometimento, obteve-se as seguintes respostas elucidativas desta questão: "Aumenta, aumenta sim, porque nosso estilo de liderança é bem participativo e com isto o comprometimento fica mais garantido. Somos sempre muito abertos ao diálogo e isto sempre facilita as coisas" (GBB 1), bem como "Sim, não vejo isto com um problema, pois nossa participação sempre é no intuito de alinharmos nossas tarefas e os parceiros são sempre muito comprometidos com cada ação que praticamos" (GBB 2).

Sob o ponto de vista dos parceiros das redes de empresas e organizações constituídas para ações ecoeficientes desenvolvidas pelos bancos, a visão não é muito diferente da verificada nos bancos. Para eles, o uso do poder não interfere na boa relação existente na rede, e com isto há sempre um bom comprometimento, conforme descrito na sequência: "Claro que sim... O comprometimento tem que existir em todas as parcerias, uma vez que vamos trabalhar para alcançarmos resultados. Não consigo imaginar isto se o comprometimento de ambas as partes não existir" (PBA 1) e ainda "Sim, claro. Somos sempre muito exigentes com os nossos produtos e com nossos serviços, com isto precisamos estar muito comprometidos com o banco em todos os projetos que participamos" (PBB 1).

\section{Poder Coercivo x Cooperação}

Relativamente à influência do poder coercivo na cooperação, os gestores dos bancos 
consideram haver a existência do poder por parte do banco, mas que esse poder em nada interfere na cooperação desenvolvida na rede pelas empresas e organizações participantes, conforme apontado nos depoimentos a seguir: "Certamente, como eu disse antes, nossos parceiros são muito envolvidos em nossos projetos e o engajamento é total, sempre participando da melhor forma possível" (GBC 1) e "Claro, sem cooperação não há trabalho, não há parceria. Precisamos estar sempre bem alinhados em todas as fases dos nossos projetos" (GBC 2).

Para os parceiros da rede de empresas e organizações constituída para ações voltadas ao desenvolvimento da ecoeficiência, a visão não é diferente da manifestada pelos gestores dos bancos envolvidos na pesquisa. Para eles, verifica-se inclusive aumento da cooperação, conforme explicitado pelos respondentes: "Claro, a nossa relação com o banco é muito clara e direta. Há uma cooperação mútua, buscamos as mesmas coisas, os mesmos resultados, não tem como não trabalharmos de outra forma" (PBB 1); "Sim, estamos trabalhando em conjunto para atingirmos nossos objetivos e esta cooperação é bem clara de ambas as partes" (PBC 1) e ainda "Com certeza, como eles cobram muito de nós, eles participam muito, nos auxiliam e são sempre atentos a tudo. Com isto a cooperação não pode deixar de existir" (PBC 2).

\section{Poder Coercivo x Confiança}

A variável confiança também não é afetada em relação à utilização do poder coercivo pelos bancos nas ações de ecoeficiência realizadas pelos agentes envolvidos nas redes de empresas e organizações constituídas, conforme constatado nos relatos abaixo manifestados pelos gestores dos bancos pesquisados, quando indagados se o uso do poder coercivo pode afetar a confiança: "Sim, a confiança é uma coisa imprescindível para nós, é o resultado dos nossos relacionamentos e não pode faltar em momento algum, pois sem confiança não há ação e nem projeto que dure" (GBA 1) e "Aumenta a confiança. A confiança é uma coisa totalmente essencial nos nossos relacionamentos, pois sem isto não tem relacionamento, não tem trabalho, não tem nenhum tipo de ação" (GBB 1).

Não muito diferente dos relatos dos gestores dos bancos pesquisados, os gestores das empresas e organizações parceiras da rede constituída para ações de ecoeficiência indicaram que a confiança também aumenta quando há poder coercivo: "Claro que sim, a confiança é fundamental para que possamos alcançar nossos objetivos. Nós trabalhamos de forma clara e sempre muito objetiva e para isto a confiança é tudo" (PBA 1) e, em complemento, "Acredito que sim, da mesma forma que temos confiança no banco, tenho a certeza que eles têm em nós. Nossa relação é muito boa, não vejo o porque de não haver confiança" (PBB 1).

Conforme verificado nos resultados da pesquisa de campo, as variáveis do Modelo de Hermans (2003) estão diretamente ligadas ao relacionamento desenvolvido nas redes de empresas e organizações constituídas para ações ecoeficientes dos bancos analisados. A pesquisa utilizou como parâmetro principal de análise o poder coercivo porventura existente nas relações entre os bancos e seus parceiros da rede de empresas e organizações constituída, buscando averiguar se o poder coercivo de alguma forma influenciava as demais variáveis: comprometimento com relacionamento, confiança e cooperação. O Quadro 2 sintetiza os principais resultados verificados na pesquisa de campo efetuada junto aos três principais bancos privados atuantes no país e as empresas e organizações inseridas em suas respectivas redes, quanto aos parâmetros presentes no modelo de Hermans (2003). 


\section{INFLUÊNCIA Do PODER COERCIVO EM REDES DE EMPRESAS}

Quadro 2

\section{Principais resultados da pesquisa de campo}

\begin{tabular}{|l|l|l|}
\hline \multicolumn{1}{|c|}{ Fatores } & \multicolumn{1}{|c|}{ Visão dos gestores dos bancos } & \multicolumn{1}{|c|}{$\begin{array}{c}\text { Visão dos gestores das empresas e } \\
\text { organizações }\end{array}$} \\
\hline Poder coercivo & $\begin{array}{l}\text { Não há poder coercivo, há sim um } \\
\text { direcionamento para deixar claros } \\
\text { os objetivos e necessidades do } \\
\text { banco. }\end{array}$ & $\begin{array}{l}\text { Sempre há, não há como se relacionar com } \\
\text { empresas grandes como o banco, sem que } \\
\text { estes não imponham suas necessidades e } \\
\text { exigências. }\end{array}$ \\
\hline $\begin{array}{l}\text { Poder coercivo X } \\
\text { Comprometimento } \\
\text { com o } \\
\text { relacionamento }\end{array}$ & $\begin{array}{l}\text { O uso do poder coercivo não } \\
\text { interfere no comprometimento e } \\
\text { aumenta as relações com os } \\
\text { parceiros. }\end{array}$ & $\begin{array}{l}\text { A visão não é muito diferente da exposta } \\
\text { pelos bancos. Para eles, o uso do poder } \\
\text { não interfere na boa relação existente na } \\
\text { rede e, com isto, há sempre um bom nível } \\
\text { de comprometimento. }\end{array}$ \\
\hline $\begin{array}{l}\text { Poder coercivo X } \\
\text { Cooperação }\end{array}$ & $\begin{array}{l}\text { A existência do poder coercivo por } \\
\text { parte do banco em nada interfere } \\
\text { na cooperação da rede de empresas } \\
\text { e organizações constituída. }\end{array}$ & $\begin{array}{l}\text { Há um claro uso do poder, pelo qual os } \\
\text { parceiros são muito cobrados. Porém, há } \\
\text { uma cooperação mútua buscando os } \\
\text { mesmos resultados de ambas as partes. }\end{array}$ \\
\hline $\begin{array}{l}\text { Poder coercivo X } \\
\text { Confiança }\end{array}$ & $\begin{array}{l}\text { Há o aumento da confiança e esta } \\
\text { confiança é essencial nos relaciona- } \\
\text { mentos entre os bancos e os } \\
\text { parceiros de rede de empresas e } \\
\text { organizações. }\end{array}$ & $\begin{array}{l}\text { O uso direto do poder coercivo não } \\
\text { interfere no relacionamento, pois a } \\
\text { confiança é um dos principais fatores para } \\
\text { o sucesso das parcerias com o banco. }\end{array}$ \\
\hline
\end{tabular}

Fonte: elaborado pelos autores.

\section{Considerações finais}

O tema meio ambiente torna-se cada vez mais relevante na agenda estratégica das organizações contemporâneas, diante da complexidade do mundo dos negócios e do atual estágio de degradação ambiental observado no planeta. A indústria bancária brasileira, considerada neste estudo a partir de seus principais bancos privados, também tem sido impactada, buscando assim promover soluções voltadas à gestão ambiental e à ecoeficiência, o que corrobora a visão expressa nos estudos de Coutinho et al. (2002), Demajorovic (2003) e Luz et al. (2006).

Tal postura ficou evidenciada por meio das ações voltadas à ecoeficiência praticadas pelos bancos e demais empresas e organizações das redes analisadas nesta pesquisa, notadamente norteadas pela economia financeira e melhoria de imagem, conforme evidenciado em estudos conduzidos por Diaz e Pires (2005), bem como Virjan (2011). Uma vez que os bancos não conseguem viabilizar sozinhos tais ações, conforme apregoam Farias Filho, Castanha e Porto (2009) e Venturini (2009), tal contexto ajudou a direcionar o objetivo do presente estudo, voltado à identificação e caracterização da existência e influência do poder coercivo nas relações desenvolvidas por grandes bancos junto à rede de empresas e organizações constituída em função de estratégia voltada à ações ecoeficientes. Para tanto, a análise teve como base o modelo proposto por Hermans (2003), que analisa o poder coercivo frente às variáveis comprometimento com relacionamento, cooperação e confiança.

Em seu estudo, Hermans (2003) atestou que o poder coercivo influencia de forma negativa a confiança e o comprometimento, concluindo ainda que se o poder coercivo é forte, as grandes instituições têm maior habilidade de forçar as empresas e organizações componentes da rede a aceitarem suas exigências. Ou seja, no estudo original do autor, a utilização de poder 
coercivo elevado diminuiu a confiança e o comprometimento, porém não diminuiu a cooperação entre os integrantes da rede.

Este estudo utilizou como parâmetros as variáveis do modelo de Hermans (2003) na pesquisa de campo efetuada junto aos gestores dos bancos e das empresas e organizações parceiras na rede constituída em prol de ações de ecoeficiência. Os principais resultados e conclusões verificadas a partir das opiniões expressas pelos gestores dos bancos e das empresas e organizações analisadas estão dispostos a seguir.

Poder Coercivo - Foi possível concluir que há utilização de poder coercivo exercido pelos bancos pesquisados junto aos seus parceiros. Porém, o poder coercivo exercido pelo banco junto aos seus parceiros é considerado pelos gestores dos bancos como orientações ou diretrizes estipuladas pelo braço forte da relação, ou seja, o banco. Já para as empresas e organizações analisadas, este poder coercivo é evidente, porém bem recebido, uma vez que não se verificaram rejeições das empresas e organizações analisadas na rede constituída em volta de cada banco pesquisado.

Poder Coercivo x Comprometimento / Poder Coercivo x Cooperação / Poder Coercivo x Confiança - Na visão dos gestores dos bancos pesquisados, bem como para os gestores das empresas e organizações atuantes na rede, a utilização do poder coercivo não diminui o comprometimento e nem a confiança existente entre os envolvidos na rede. Consequentemente, também não se verificou influência na cooperação desenvolvida entre os integrantes da rede, conforme relatado nas falas dos gestores entrevistados. Tais resultados corroboram estudos anteriores de Lundin (2007), Hanna e Walsh (2008) e Delfim Neto (2009), que evidenciam a importância do comprometimento, confiança e cooperação para o sucesso de organizações atuantes em redes de empresas.

Nas variáveis analisadas verificou-se haver um consenso entre os gestores dos bancos e os gestores das empresas e organizações pesquisadas, atuantes nas redes analisadas. Pôde-se verificar que o comprometimento no relacionamento aumenta sensivelmente a cooperação e a confiança entre os agentes envolvidos, sendo a confiança a principal variável para os gestores entrevistados, que afirmaram que quanto mais se confia no seu parceiro, melhor é a cooperação entre todos os envolvidos na rede estabelecida.

Os resultados da pesquisa de campo apontaram que os bancos pesquisados têm maior habilidade para forçar os parceiros de sua rede de empresas e organizações a aceitarem as suas exigências. Com isto, concluiu-se que há utilização de poder coercivo no caso dos bancos, mesmo que isto não seja considerado poder coercivo por parte dos gestores dos bancos, mas sim como orientações e diretrizes impostas pelo elo mais forte da relação. Para os parceiros da rede este poder coercivo é claro, porém bem recebido, não havendo assim rejeições por parte dos gestores das empresas e organizações participantes das redes constituídas analisadas.

Para os gestores dos bancos, bem como os gestores das organizações e empresas parceiras da rede, a utilização do poder coercivo, diferentemente do evidenciado pelo modelo de Hermans (2003), não diminui o comprometimento e nem a confiança e, com isto, acaba por não influir na cooperação entre os integrantes da rede.

Uma limitação do presente estudo diz respeito ao processo de coleta de dados da pesquisa de campo. Eventualmente poder-se-á encontrar algumas barreiras em função da confidencialidade das informações prestadas, principalmente caso os gestores dos bancos e demais empresas e organizações analisadas julguem que tais informações possam ser consideradas estratégicas à respectiva organização. 


\section{INFLUÊNCIA DO PODER COERCIVO EM REDES DE EMPRESAS}

Embora sejam evidentes as limitações inerentes à presente pesquisa, fica clara a contribuição de se estudar o setor de serviços e, mais especificamente, o setor financeiro, destacando-se para tanto a indústria bancária brasileira como um grande campo de estudo para os pesquisadores e profissionais ligados à área de gestão ambiental.

A contribuição acadêmica deste estudo volta-se ao avanço do tema que, embora seja objeto de pesquisas já executadas principalmente em empresas industriais, não se demonstra farta quanto a estudos específicos voltados às empresas prestadoras de serviços. Ainda mais em se tratando do relacionamento entre bancos e organizações parceiras voltadas ao desenvolvimento de ações de ecoeficiência em redes de empresas. Assim sendo, a construção de um referencial teórico amplo e a aplicação dos conceitos de gestão ambiental na prática, podem indicar caminhos a serem seguidos pelos demais pesquisadores, bem como contribuir na construção e desenvolvimento do pensamento científico acerca do tema.

\section{Referências}

AALL, C.; HUSABO, I. A. Is eco-efficiency a sufficient strategy for achieving a sustainable development? The Norwegian Case.Sustainability, 2010.

AMATO NETO, J. Redes de cooperação produtiva e clusters regionais: oportunidades para as pequenas e médias empresas. São Paulo: Atlas, 2000.

ANVARI, R.; AMIN, S. M. Commitment, involvement and satisfaction in relationship marketing. Interdisciplinary Journal of Contemporary Research in Business. Canterbury, v. 1, n. 11, p. 51-70, 2010.

BARBIERI, J. C. Organizações inovadoras sustentáveis. In: BARBIERI, J. C; SIMANTOB, M (Orgs). Organizações inovadoras sustentáveis: uma reflexão sobre o futuro das organizações. São Paulo, Atlas, 2007, p 15 - 24.

BRADESCO - Banco Brasileiro de Descontos. Finanças sociais 2011. São Paulo: Bradesco, 2011.

CÂNDIDO, G. A.; ABREU, A. Fatores críticos de sucesso no processo de formação, desenvolvimento e viabilização de redes organizacionais: um estudo exploratório. In: EnANPAD, XXVIII, 2004, Curitiba, Anais... Rio de Janeiro: ANPAD, 2004, p. 16-31.

CO, R.; BOOTH, A.; LOUIS, B. Eco-efficiency and SMEs. Journal of Cleaner Production, v. 14, p. 542-550, 1994.

COUTINHO, R. B. G.; MACEDO-SOARES, T. D. L. V. A.; SILVA, J. R. G. Projetos sociais de empresas no Brasil: arcabouço conceitual para pesquisas empíricas e análises gerenciais. Revista de Administração Pública. v. 40, n. 5, p. 76-78, 2002.

DAHLSRUD, A. How corporate social responsibility is defined. Corporate Social Responsibility and Environmental Management. v. 15, n. 1, p.1-13, 2009.

DELFIM NETO, A. Economista produz crise, mas não sabe resolvê-la. 0 Estado de São Paulo: São Paulo; 02 de janeiro de 2009.

DEMAJOROVIC, J. Sociedade de risco e responsabilidade socioambiental: perspectivas 
para educação corporativa. São Paulo: Senac, 2003.

DESIMONE, L. D.; POPOFF, F. Eco-efficiency: The business link sustenaible development. Cambridge: MIT Press, 2000.

DIAZ, C. A. P.; PIRES, S. R. I. Produção mais limpa: integrando meio ambiente e produtividade. Revista de Administração CREUPI, v. 5, n. 9, jan./dez. 2005.

FARIAS FILHO, J.R; CASTANHA, A.L.B.; PORTO, C.B. Arquiteturas em redes: Um novo paradigma competitivo para as micro, pequenas e médias empresas. In: EnANPAD, XXXIII, 2009. São Paulo, Anais... Rio de Janeiro: ANPAD, 2009. p. 15-30

FEBRABAN - Federação Brasileira de Bancos. 0 setor bancário. São Paulo. 2011.

FERREIRA, A. B. H. Novo aurélio: o dicionário da língua portuguesa. Rio de Janeiro: Nova Fronteira, 1999.

GALDINO, C. A. B. et al. Passivo ambiental: revisão teórica de custos na indústria do petróleo. Gestão e Produção. v. 14, n. 1, p. 54-63. 2004.

GRANDORI, A.; SODA, G.: Inter firm networks: antecedents, mechanism and forms. Organization Studies, v. 16, n. 2, p. 183-214, 1995.

HANNA, V.; WALSH, K. Cooperation among small manufacturing firms. International Small Business Journal. Cheshire, v. 26, n. 3, p. 299-321, 2008.

HERMANS, C. M.; Direct and indirect effects of coercive power in the commitment trust theory of relationship marketing. $224 \mathrm{f}$. Tese (Doutorado em Filosofia em Administração) New Mexico State University. New Mexico, 2003.

HERTWICH, E. D. Life cycle approaches to sustainable consumption: a critical review. Environmental Scientific Technolology, v. 39, p. 838, 2009.

ITAÚ - Banco Itaú. Balanço social 2011. São Paulo: Itaú, 2011.

JARILLO, J. C. On strategic networks. Strategic Management Journal, v. 9, p. 31-41, 1988.

KIM, W. C.; MAUBORGNE, R. Blue ocean strategy book. How to create uncontested market space and make the competition irrelevant leadership excellence. 2007.

KOLARZ-CZAPLICKA, K. KOROL-BURCHART, D. e KRAWCZYK, P. Eco-efficiency analysis methodology on the example of the chosen polyolefins production, Journal of Achievements in Materials and Manufacturing Engineering, v. 43, n. 1, p. 469-475, 2010.

LARANGEIRA, S. M. G. Reestruturação em bancos e telecomunicações no Brasil:excluídos e beneficiados. In: Cinterfor - Centro Interamericano para el Desarrollo del Conocimiento en la Formación Profesional Trabajo, Género y Ciudadanía en los Países del Cono Sur. Montevideo: 1998.

LEHNI, M. Eco-efficiency: creating more value, with less impact. Genebra: WBCSD, 2000.

LUNDIN, M. Explaining cooperation: how resource interdependence, goal congruence, and trust affect joint actions in policy implementation. Journal of Public Administration 


\section{INFLUÊNCIA DO PODER COERCIVO EM REDES DE EMPRESAS}

Responsability Theory, v. 17, n. 4, p. 651-672. 2007.

LUZ, S. O. C; SELLITTO, M. A; GOMES, L. P. Medição de desempenho ambiental baseada em método multicriterial de apoio à decisão: estudo de caso na indústria automotiva. Gestão e Produção, São Carlos, v. 13, n. 3, p. 557-570, 2006.

MACHADO-DA-SILVA, C. L.; FONSECA, V. S. Competitividade organizacional: uma tentativa de reconstrução analítica. Revista de Administração Contemporânea, São Paulo, v.14, p. 3349, 2010.

MICHELSEN, O.; DAHLSRUD, A. Eco-efficiency in extended supply chains: a case study of furniture production, Journal of Environmental Management, v. 79, p. 290-297, 2009.

MIRATA, M.; EMTAIRAH, T. Industrial symbiosis networks and the contribution to environmental innovation: the case of the Landskrona industrial symbiosis programme. Journal of Cleaner Production, v. 13, n. 10-11, p. 993-1002, Aug./Sep. 2005.

MORGAN, Robert M.; HUNT, Shelby D. The commitment-trust theory of relationship marketing. Journal of Marketing. Chicago, v. 58, p. 20-38, 1994.

PASQUALI, L. Instrumentos psicológicos: manual prático. Brasília: LabPAM/IBAPP, 2007.

RACHID, A. Relações entre grandes e pequenas empresas de auto-peças: um estudo sobre a difusão de práticas de organização da produção. 202 f. Tese (Doutorado em Engenharia Mecânica) - Universidade Estadual de Campinas. Campinas, 2000.

SANTANDER - Banco Santander Brasil. Balanço social 2012. São Paulo: Santander, 2012.

SOETOMO, H. Power-trust-commitment in relationship marketing. Tese (Doutorado em Administração) - Wayne Huizenga Graduate School of Business and Entrepreneurship of New Southeastern University. Florida. 2001

THANT, K.; CHARMONDUSIT, A. Eco-efficiency assessment of pulp and paper industry in Myanmar, Clean Technologies and Environmental Policy, v. 12, p. 427-439, 2010.

VASCONCELOS, F. C. Safári de estratégia, questões bizantinas e a síndrome do ornitorrinco: uma análise empírica dos impactos da diversidade teórica em estratégia empresarial sobre a prática dos processos de tomada de decisão estratégica. In: EnANPAD, XXV, 2001. São Paulo, Anais... Rio de Janeiro: ANPAD, 2000, p. 1-15.

VIRJAN, D. The rethinking of the economic activity based on principles of eco-efficiency, Theoretical and Applied Economics, v. XVIII, n. 7 (560), p. 143-154, 2011.

WORLD BUSINESS COUNCIL FOR SUSTAINABLE DEVELOPMENT. Eco-efficient leadership forimproved economic and environmental performance. 1996.

Eco-efficiency. New York: WBCSD, 2002. 